\title{
Hemophagocytic lymphohistiocytosis: a review inspired by the COVID-19 pandemic
}

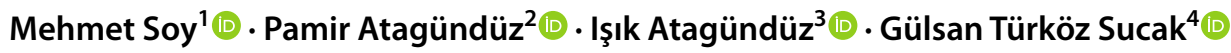

Received: 26 April 2020 / Accepted: 19 June 2020 / Published online: 25 June 2020

๑) Springer-Verlag GmbH Germany, part of Springer Nature 2020

\begin{abstract}
Hemophagocytic syndrome (HPS) or hemophagocytic lymphohistiocytosis (HLH) is an acute and rapidly progressive systemic inflammatory disorder characterized by cytopenia, excessive cytokine production, and hyperferritinemia. Common clinical manifestations of HLH are acute unremitting fever, lymphadenopathy, hepatosplenomegaly, and multiorgan failure. Due to a massive cytokine release, this clinical condition is considered as a cytokine storm syndrome. HPS has primary and acquired (secondary, reactive) forms. Its primary form is mostly seen in childhood and caused by various mutations with genetic inheritance and, therefore, is called familial HLH. Secondary HLH may be caused in the presence of an underlying disorder, that is, secondary to a malignant, infectious, or autoimmune/autoinflammatory stimulus. This paper aims to review the pathogenesis and the clinical picture of $\mathrm{HLH}$, and its severe complication, the cytokine storm, with a special emphasis on the developed classification criteria sets for rheumatologists, since COVID-19 infection has clinical symptoms resembling those of the common rheumatologic conditions and possibly triggers HLH. MED-LINE/Pubmed was searched from inception to April 2020, and the following terms were used for data searching: "hemophagocytic syndrome" OR "macrophage activation syndrome" OR "hemophagocytic lymphohistiocytosis", OR "cytokine storm". Finally, AND "COVID-19" was included in this algorithm. The selection is restricted to the past 5 years and limited numbers of earlier key references were manually selected. Only full-text manuscripts, published in an English language peer-reviewed journal were included. Manuscript selection procedure and numbers are given in Fig. 2. Briefly, the database search with the following terms of "Hemophagocytic syndrome" OR "Macrophage activation syndrome" OR "Hemophagocytic lymphohistiocytosis" OR "Cytokine storm" yielded 6744 results from inception to April 2020. The selection is restricted to the past 5 years and only limited numbers of earlier key references were selected, and this algorithm resulted in 3080 manuscripts. The addition of (AND "COVID-19") resulted in 115 publications of which 47 studies, together with four sections of an online book were used in the final review. No statistical method was used. HLH is triggered by genetic conditions, infections, malignancies, autoimmune-autoinflammatory diseases, and some drugs. In COVID-19 patients, secondary HLH and cytokine storm may be responsible for unexplained progressive fever, cytopenia, ARDS, neurological and renal impairment. Differentiation between the primary and secondary forms of HLH is utterly important, since primary form of HLH requires complicated treatments such as hematopoietic stem cell transplantation. Further studies addressing the performance of HScore and other recommendations in the classification of these patients is necessary.
\end{abstract}

Keywords Hemophagocytic syndrome $\cdot$ Hemophagocytic lymphohistiocytosis $\cdot$ Macrophage activation syndrome . Cytokine storm syndrome

Pamir Atagündüz

pamir.atagunduz@gmail.com

Extended author information available on the last page of the article

\section{Introduction}

Hemophagocytic lymphohistiocytosis (HLH) comprises two different conditions that may be difficult to distinguish from one another: A primary form that occurs due to genetic disorders and a secondary form that is triggered by various infections, autoimmune/autoinflammatory diseases, or chemicals $[1,2]$. Recent reports suggest that the cytokine 
storm caused by the novel Coronavirus infection, COVID19 , has significant similarities with the clinical and laboratory findings of this disorder. Due to the accelerated deterioration of patients' general status, hemophagocytic syndrome (HPS) necessitates a timely diagnosis for the initiation of life-saving treatment.

HPS or HLH is an acute and rapidly progressive systemic inflammatory disorder characterized by cytopenia, excessive cytokine production, and hyperferritinemia. Common clinical manifestations of HLH are acute unremitting fever, lymphadenopathy, hepatosplenomegaly, and multiorgan failure. Due to a massive cytokine release, this clinical condition is considered as a cytokine storm syndrome. HLH has primary and acquired (secondary, reactive) forms. Its primary form is mostly seen in childhood and caused by various mutations with genetic inheritance and, therefore, is called familial HLH (fHLH) (Fig. 1). Secondary HLH (sHLH) may be caused in the presence of an underlying disorder, that is, secondary to a malignant, infectious, or autoimmune/autoinflammatory stimulus [1-3]. This clinical condition was first reported by Scott et al. in 1939. The first reported four cases were identified as atypical Hodgkin's Lymphoma, characterized by pronounced histiocytic erythro-phagocytosis in the bone marrow and cellular proliferation in the lymph nodes, medulla of the spleen and the periportal area. Later, Scott et al. named this clinical entity as histiocytic medullary reticulocytosis (HMR) because of the pronounced phagocytosis with intense hyperplasia in medullary areas. In the light of the data obtained, it was accepted as a welldifferentiated reticulum cell sarcoma, a malignant process until 1973. In 1991, it was designated as Hemophagocytic Lymphohistiocytosis The term of Macrophage Activation Syndrome (MAS) was used first in 1993. In 1997, the HLH working group classified the HPS into primary and secondary HLH [4-6].

In this review, we aim to contribute to the rheumatologists' awareness of the life-threatening rare complication of HLH, the cytokine storm, to prevent a possible misdiagnosis in the presence of the clinical and laboratory features of COVID-19 resembling or mimicking to that of an underlying or a new-onset rheumatological condition. We hope that this review will support the collaboration of the rheumatologist and hematologists with their colleagues, who treat COVID-19 patients in the first place, such as the infectious disease specialists, pneumologists, or intensive care physicians.



Fig. 1 Classification 


\section{Methods}

\section{Study selection}

Manuscript selection procedure and numbers are given in Fig. 2. Briefly, MED-LINE/Pubmed was searched from inception to April 2020, and the following terms were used for data searching: "Hemophagocytic syndrome" OR "Macrophage activation syndrome" OR "Hemophagocytic lymphohistiocytosis", OR "Cytokine storm". To increase the weight of the recent publications, the selection is restricted to the past 5 years and only limited numbers of earlier key references were manually selected. Finally, (AND "COVID19") was applied in this algorithm. Only full-text manuscripts, published in an English language peer-reviewed journal were included. Free full-text articles available at https://pubmed.ncbi.nlm.nih and selected full-text articles indexed in Web of Science or Scopus are downloaded using the EBSCO Discovery services.

The author MS collected data and wrote the manuscript. The authors GTS and IA carefully reviewed the data from the perspective of a hematologist. And the author PA reviewed the article for both immunologic and rheumatologic aspects, prepared tables, translated into English, and gave the manuscript's final form. No statistical method was used.

\section{Results}

The database search with the following terms of "Hemophagocytic syndrome" OR "Macrophage activation syndrome" OR "Hemophagocytic lymphohistiocytosis" OR "Cytokine storm" yielded 6744 results from inception to April 2020. When the selection is restricted to the past 5 years and only limited numbers of earlier key references were selected, this algorithm resulted in 3080 manuscripts and the addition of AND "COVID-19" resulted in 115 publications of which 47 studies, together with four sections of an online book were used in the final review. Only full-text manuscripts, published in an English language peer-reviewed journal were included. We used data only from the index papers for table creation and figures.

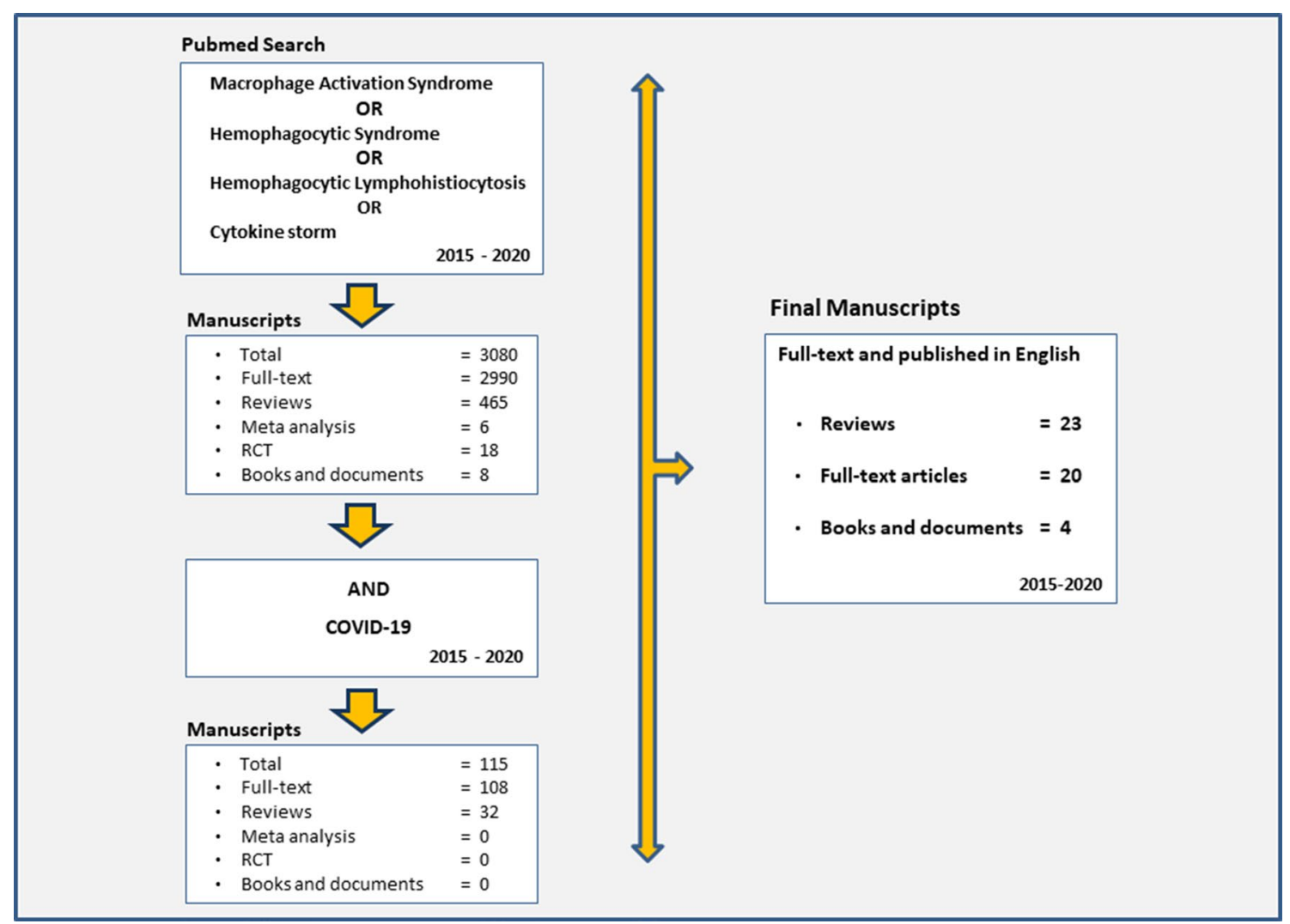

Fig. 2 Article selection process 


\section{Discussion}

\section{Primary hemophagocytic lymphohistiocytosis (pHLH)}

About a quarter of total pHLH cases have a genetic transition, and therefore, it is advisable to question a history of consanguineous marriage. Infections, especially viral, frequently trigger an inappropriate cytotoxic immune response in the presence of some genetic conditions. Mutations in $\mathrm{CD} 8^{+} \mathrm{T}$ cells and natural killer (NK) cells (homozygous, compound heterozygous, or digenic (with heterozygous mutations in two different genes) result in a loss of performance in the cytolytic pathway proteins such as PRF1, STX11, UNC13D, and UNC18-2. The pathogenesis of this syndrome is underlined by the activation and proliferation of $\mathrm{T}$ lymphocytes (Mainly $\mathrm{CD} 8{ }^{+}$cytotoxic $\mathrm{T}$ cells), and natural killer (NK) cells leading to over-activation and proliferation of macrophages resulting in the phagocytosis of bone marrow hematopoietic cells and/or reticuloendothelial system cells in other organs with the hypersecretion of several cytokines including interferongamma (IFN- $\gamma$ ), interleukin (IL)-1, IL-6, IL-18, and tumor necrosis factor-alpha (TNF $\alpha)[5,7]$ (Fig. 3).
The most important immunological abnormality in primary or reactive HLH is the impaired cytotoxic cell function. Under normal physiological conditions, when a virusinfected cell or tumor cell is encountered, $\mathrm{CD} 8^{+}$cytotoxic $\mathrm{T}$ cells, NK and NKT cells release perforin (a tetrameric protein that creates pores in the target cell, facilitates the entry of granzymes, and disrupts the target cell's membrane) containing cytolytic granules, and granzymes (proteins involved in triggering apoptosis in the target cell) initiate cytolytic destruction of the target cell. For this process to proceed normally, perforin and granzymes must be structurally normal and properly distributed in the cell and packaged into granules. Then the content of these granules should enter the target cell via exocytosis through the immunological synapse between the cytotoxic cell and its target. Disruption of this process with genetic mutations leads to the development of primary or familial HLH. Under normal conditions, perforin and granzymes contribute to the destruction of target cells and the elimination of the immune-activating stimulus; this eventually results in apoptosis of cytotoxic cells, together with reduced antigen stimulation. This physiological downregulation, called activation-induced cell death, is critical for the control of the immune response. Failure to clear the antigenic stimulus for any reason results in persistence and strengthening of the immune response. Immune activation



Fig. 3 Pathogenesis and clinical findings 
is further driven by the high levels of macrophage activation, with proinflammatory cytokines released by activated immune cells, resulting in hemophagocytosis, tissue damage, organ failure, and other inflammatory symptoms of the syndrome $[2,4,8,9]$. Numerous serum proinflammatory cytokine levels, including IL-1, IL-2, IL-6, IL-12, IL-16, IL-18, TNF- $\alpha$, and IFN- $\gamma$, were found to be significantly high in HLH patients sera. The patient's prognosis worsens as the levels of these cytokines increase. Inability to clear antigenic stimulation of certain infections, malignant or autoimmune/autoinflammatory processes leads to an inappropriate immune stimulation and a self-sustaining hyper-inflammatory condition known as the cytokine storm, characterized by excessive and persistent high cytokines levels listed above [9]. HLH may be classified as a cytokine storm syndrome in the presence of the intense and rapid cytokine elevation. Cytokine storm has emerged as an important, under-recognized cause of death in COVID-19 [10, 11]. High levels of anti-inflammatory cytokines have also been observed in $\mathrm{HLH}$, especially the overproduction of IL-10, indicating a mechanism, albeit insufficient, to suppress the hyperactivation of Th1 cells and monocyte/macrophage functions in patients with this disease [9]. The source of IL-10 probably is the hemophagocytes and this may imply that hemophagocytosis is a compensatory reaction to $\operatorname{HLH}[12,13]$. In pHLH and related immunodeficiency syndromes, the inheritance of defective genes involved in the control of cytolysis (e.g., PRF1, STX11, UNC13D, UNC18-2) leads to the uncontrolled proliferation and survival of $\mathrm{CD} 8^{+} \mathrm{T}$ Cells by impairing the cytolytic activity of cytotoxic T Lymphocytes $[5,7]$. Children with certain immunodeficiency syndromes, such as Chédiak-Higashi syndrome, Hermansky-Pudlak syndrome Type II, Griscelli syndrome (partial albinism), X-linked lymphoproliferative disease, XMEN disease, ITK (interleukine-2-inducible T cell kinase deficiency), Lysinuric protein intolerance, CD27 deficiency, and chronic granuloma also possess genetic defects associated with impaired cytolysis and are at risk of developing familial HLH. Specific X-linked immune deficiencies such as signaling lymphocytic activation molecule associated protein (SAP) and $\mathrm{X}$-linked apoptosis inhibitor (XIAP) deficiency, are also associated with HLH triggered by the Epstein-Barr virus (EBV) $[3,5,14]$. pHLH is a rare (1/50,000 of all live births) condition and usually develops in the very first years of life. It should be kept in mind that pHLH as accepted widely as a pediatric disease, may develop its first symptoms in adulthood. Patients with sHLH may have cytolytic genes with underlying hypomorphic defects found in pHLH, as well. Indeed, up to $40 \%$ of sHLH and MAS patients are reported to carry heterozygous (some dominant-negative) mutations of known familial HLH genes. Therefore, some researchers suggest that MAS, sHLH, and familial HLH may be considered as members of a disease spectrum [3, 5, 7]. It is an interesting finding that the prevalence of some mutations differs in certain populations such as those who are linked to perforin mutations that are more common in Turks $[15,16]$.

On the other hand, unlike primary HLH patients, observed differences in the pattern of $\mathrm{T}$ lymphocyte activation and differentiation in sHLH patients may imply differences in the pathogenesis of these two conditions. For example, Amman et al. demonstrated that the expression of HLA DR4 and perforin in activated CD8 T cells were higher in genetically predisposed HLH patients [17]. It has been shown that lymphomas resulting in sHLH produce proinflammatory cytokines that initiate and permanently stimulate the activation of cytotoxic T lymphocytes and NK cells as the triggers of this syndrome. Epstein-Barr virus (EBV) is the most common infectious trigger for both primary and secondary HLH. An interesting finding in this association is that EBV, which normally infects B lymphocytes, can also infect $\mathrm{CD}^{+}$cytotoxic $\mathrm{T}$ lymphocytes, resulting in EBVassociated HLH [4].

\section{Secondary HLH and MAS}

Secondary forms of HLH can be triggered by infections, malignancies, autoimmune/autoinflammatory diseases, and medications. Most frequently, sHLH is triggered by infections (termed as HLH-associated with infection). In some cases, a history of traveling is present. In particular, infectious of especially EBV and other members of the Herpesvirus family, HIV, bacteria, and fungi are the triggers of this clinical picture. Malignancies, especially leukemia or lymphoma (termed as HLH-associated with malignancy) are among common triggers [14]. HLH, which develops in association with an autoimmune/autoinflammatory rheumatological disease, is often referred to as MAS and will be discussed in detail below. However, it is worth pointing out that some authors prefer to use the term MAS for secondary HLH. Interestingly, secondary HLH may arise iatrogenically due to drugs used in the treatment of the primary disease. In 2014, Ramos-Callas et al. reported in a meta-analysis of 775 HLH cases that the disease was more frequent in Japan, France, China, South Korea, Taiwan, Italy, Spain, and Turkey [1]. Infections and drugs were the most common reported causes in adults, while at least $30 \%$ had three or more possible triggering factors. The distribution of the causes varied between countries. Malignancies were the leading cause in Japan, S. Korea, Taiwan, China, France, and Italy, whereas autoimmune diseases were more frequent in Spain and the USA.

\section{Macrophage activation syndrome}

Secondary HLH, which develops in the context of rheumatological diseases, is often referred to as MAS and is reported 
most frequently in systemic Juvenile Idiopathic Arthritis (sJIA, Still Disease) patients [5]. Strippoli et al. suggested a trilayer mechanism for the HLH that is secondary to rheumatic diseases: Firstly, a genetic tendency (such as defects in the cytotoxic activity of CD8 and NK cells and a genetic predisposition to TLR hyper-response), followed by a high disease activity caused by the high proinflammatory state mediated by the high levels of cytokines such as IL-6, and finally the activation of immune cells such as the $T$ cells and macrophages triggered by a viral infection that leads to the cytokine storm [19].

Up to $10 \%$ of sJIA cases develop MAS. In adults, it is reported in association with cases of adult onset still disease (AOSD), and to a lesser extent in Systemic Lupus Erythematosus (SLE) cases. MAS is a not well known but life-threatening complication of these rheumatic diseases. Similar to sJIA, $10-15 \%$ of AOSD patients develop MAS. The activation of shared innate immunopathogenic pathways, including IL-1 and IL-18, leads to a similar systemic inflammation in both AOSD and SJIA. Therefore, it is not surprising that MAS is a common complication of both diseases [20, 21]. This hypothesis is supported by the observation that gain-offunction mutations in the gene encoding the innate immune protein NLRC4 promote the spontaneous formation of the NLRC4 inflammasome, production of IL-1 family cytokines (IL-1 $\beta$ and IL-18) and inflammatory cell death in autoinflammatory diseases complicated by MAS [22]. Similar to sJIA, MAS in AOSD may either occur at onset ora later stage, mostly triggered by viral infections [23]. In some patients, MAS may lead to ARDS and death in the course of COVID-19 infection [10, 24, 25]. Therefore, MAS should be kept in mind in a COVID-19 patient with signs of rapid clinical and laboratory deterioration. Every rheumatologist should be alert because of the cytokine storm, a severe complication of COVID-19, and symptoms of COVID-19 such as fever, arthralgia, and myalgia resembling those seen during several rheumatologic diseases [26].

MAS occurring in the early stages of AOSD is characterized by neutrophilic leucocytosis and this laboratory finding may be used in the differential diagnosis. Later in the course of AOSD MAS may coincide with disease flares, infections, or the use of anti-inflammatory drugs such as sulfasalazine, methotrexate, hydroxychloroquine, and anti-TNF agents. Secondary HLH (MAS) is characterized by fever, pulmonary insufficiency, liver failure, neurological symptoms, and signs of pancytopenia and coagulopathy that could not be explained for any other reason. Instead of a fever that rises typically in the afternoons with chills in AOSD, unremitting fever is more common in the presence of MAS. Therefore, persistent fever despite the treatment of infections that develops in the course of SJIA or AOSD should raise the suspicion of MAS $[27,28]$. Pulmonary involvement is found in about half of sHLH patients and patients may develop acute respiratory distress syndrome (ARDS), which requires mechanical ventilation. ARDS has a poor prognosis and is more common in severe sHLH requiring intensive care [29]. Neurological involvement is a sign of poor prognosis, as well, and is usually a sign of established sHLH. Several clinical signs and symptoms of CNS involvement ranging from mood and personality changes to seizures, muscle weakness in the extremities, cranial nerve palsy, decreased consciousness, and coma, may develop. Acute renal failure necessitating chronic renal replacement may be seen and worsens the outcome [30-33]. In AOSD and MAS cases, leukocyte and platelet count, hemoglobin, albumin, and fibrinogen levels are significantly lower than non-MAS AOSD cases. However, ferritin, LDH, and triglyceride levels (which develops due to TNF $\alpha$ suppression of lipoprotein lipase) are significantly higher in patients with MAS [5, 27]. Here, serum ferritin levels are of critical value in diagnosis. The probability of MAS at levels below $500 \mathrm{ng} / \mathrm{ml}$ is rather weak. While the probability of MAS increases for values between 500 and 1000 , a value of $10,000 \mathrm{ng} / \mathrm{ml}(10,000 \mu / \mathrm{L})$ or higher has a $96 \%$ specificity and $90 \%$ sensitivity for the presence of MAS. Ferritin is the most dynamic test that rises rapidly and extensively in the early inflammatory period and decreases significantly with active treatment and cessation of the inflammation. The ratio between baseline and recovery may reach $1-800$. High levels persisting despite active treatment or a decline of less than $\% 50$ is associated with a poor prognosis. Pre- and posttreatment levels of the laboratory parameters such as D-dimer, triglycerides, platelet levels, $\mathrm{LDH}$, and transaminases differ as much as about $\% 50$ and may be useful in the diagnosis. The presence of hyperferritinemia in association with cytopenia in various series, low levels of fibrinogen (due to the procoagulant effects of TNF $\alpha$ or increased lysis), and the absence of a significant increase in sedimentation despite the increased CRP may be used to support the diagnosis of MAS [34]. Thrombocytopenia and hypofibrinogenemia can lead to ecchymoses and bleeding, especially in critical cases. Since hemophagocytosis is a late-stage finding, it may not be detected in early bone marrow examinations. Bone marrow findings may not correlate with clinical symptoms or high ferritin levels and are, therefore, not essential for diagnosis $[30,34]$. One should not wait for hemophagocytosis to be proven to initiate treatment, but a bone marrow biopsy, when available, is necessary, since hemophagocytosis in the bone marrow may support the therapy when present.sCD25 as a marker of T cell activation, and SCD163 as the marker of hemophagocytosis, are specific markers for HLH. However, the aforementioned parameters are not included in the MAS classification criteria made for SJIA due to difficulties in their routine use [35]. But, the HLH-2004 criteria include $\operatorname{sCD} 25(\operatorname{sIL} 2 \mathrm{R} \alpha) \geq 2400 \mathrm{U} / \mathrm{ml}[34]$. 
In summary, it is crucial to exclude HLH/MAS in sJIA, AOSD, and when patients with COVID-19 suddenly deteriorate in the presence often remitting high fever, additional pulmonary, and/or neurological symptoms, cytopenia, and abnormal ferritin or LDH levels [24, 25, 36].

\section{Diagnostic tools: HLH-2004 score, HScore, MH score}

A timely diagnosis of HLH is of particular importance, because patients may be critically ill and delay in diagnosis contributes only to a poor outcome.

The diagnosis is based mainly on clinical and laboratory criteria. There is no single laboratory test or clinical finding that is pathognomonic. The widely used HLH-2004 criteria set is developed by the Histiocyte Society (Table 1) [37].

Table 1 Diagnostic guidelines for hemophagocytic syndrome (HPS) or hemophagocytic lymphohistiocytosis (HLH)

\begin{tabular}{|c|c|c|c|c|}
\hline Clinical/laboratory findings & HLH-2004 & HScore $^{\mathrm{c}}$ & MH score ${ }^{\mathrm{c}, \mathrm{d}}$ & sJIA/MAS \\
\hline Fever $\left({ }^{\circ} \mathrm{C}\right)$ & $\geq 38.5$ & $\begin{array}{l}<38.4: 0 \text { points } \\
\text { 38.4-39.4: } 33 \text { points } \\
>39.4: 49 \text { points }\end{array}$ & - & + \\
\hline Organomegaly & Splenomegaly & $\begin{array}{l}\text { Absent: } 0 \text { points } \\
\text { Hepatomegaly or splenomeg- } \\
\text { aly: } 23 \text { points Hepatomegaly } \\
\text { and splenomegaly: } 38 \text { points }\end{array}$ & $\begin{array}{l}\text { Splenomegaly: } \\
\text { Absent: } 0 \text { points } \\
\text { Present: } 12 \text { points }\end{array}$ & - \\
\hline Cytopenia & $\begin{array}{l}\text { Cytopenia of } \geq 2 \text { series } \\
\text { Hemoglobin }<9 \mathrm{~g} / \mathrm{dL} \\
\text { Platelet count }<100 \times 10^{9} / \mathrm{L} \\
\text { Absolute neutrophil count } \\
\quad<1 \times 10^{9} / \mathrm{L}\end{array}$ & $\begin{array}{l}\text { Single series: } 0 \text { points } \\
\text { Two series: } 24 \text { points } \\
\text { Three series: } 34 \text { points }\end{array}$ & $\begin{array}{l}\text { Neutrophil count } \\
>1.4: 0 \text { points } \\
\leq 1.4, \times 10^{9} / \mathrm{L}: 37 \text { points } \\
\text { Platelet: } \\
>78: 0 \text { points } \\
\leq 78, \times 10^{9} / \mathrm{L}: 11 \text { points } \\
\text { Hemoglobin } \\
>8.3: 0 \text { points } \\
\leq 8.3, \text { g/dL: } 11 \text { points }\end{array}$ & $\begin{array}{l}\text { Platelet count } \\
\quad \leq 181 \times 10^{9} / \mathrm{L}\end{array}$ \\
\hline Triglycerides $^{\mathrm{a}}(\mathrm{mmol} / \mathrm{L})$ & $\begin{array}{l}\text { Hypertriglycemia and/or } \\
\text { hypofibrinogenemia } \\
\text { Triglycerides } \geq 3,0(65 \mathrm{mg} / \mathrm{dL})\end{array}$ & $\begin{array}{l}<1.5: 0 \text { points } \\
\text { 1.5-4. } 0: 44 \text { points } \\
>4.0: 64 \text { points }\end{array}$ & & $>156 \mathrm{mg} / \mathrm{dl}$ \\
\hline Fibrinogen $(\mathrm{mg} / \mathrm{dL})^{\mathrm{a}}$ & $\begin{array}{l}\text { Fibrinogen } \leq 150 \mathrm{mg} / \mathrm{dl}, \\
\quad(1.5 \mathrm{~g} / \mathrm{l})\end{array}$ & $\begin{array}{l}>2.5: 0 \text { points } \\
\leq 2.5: 30 \text { points }\end{array}$ & $\begin{array}{l}>131: 0 \text { points } \\
\leq 131 \mathrm{mg} / \mathrm{dl}: 15 \text { points } \\
(1.31 \mathrm{~g} / \mathrm{l})\end{array}$ & $\leq 360 \mathrm{mg} / \mathrm{dl}$ \\
\hline Ferritin (ng/L) & $\geq 500 \mu \mathrm{g} / \mathrm{L}$ & $\begin{array}{l}<2000: 0 \text { points } \\
\text { 2000-6000: } 35 \text { points } \\
>6000: 50 \text { points }\end{array}$ & & $>684 \mathrm{ng} / \mathrm{ml}$ \\
\hline Serum AST (IU/L) & - & $\begin{array}{l}<30: 0 \text { points } \\
\geq 30: 19 \text { points }\end{array}$ & & $>48 \mathrm{U} / \mathrm{L}$ \\
\hline $\begin{array}{l}\text { Hemophagocytosis in the bone } \\
\text { marrow }\end{array}$ & $\begin{array}{l}\text { Hemophagocytosis in the bone } \\
\text { marrow, spleen or the lymph } \\
\text { nodes }\end{array}$ & $\begin{array}{l}\text { Absent: } 0 \text { points } \\
\text { Present: } 35 \text { points }\end{array}$ & & \\
\hline Immunosupression $^{\mathrm{b}}$ & - & $\begin{array}{l}\text { Absent: } 0 \text { points } \\
\text { Present: } 18 \text { points }\end{array}$ & & \\
\hline NK cell activitiy & Low or absent & - & & \\
\hline sCD25 (sIL2R $\alpha)$ & $\geq 2400 \mathrm{U} / \mathrm{ml}$ & - & & \\
\hline Age at onset (years) & - & - & $\begin{array}{l}>1.6: 0 \text { points } \\
\leq 1.6: 37 \text { points }\end{array}$ & - \\
\hline
\end{tabular}

${ }^{\mathrm{a}}$ Are used as single parameters for HLH-2004 scoring

${ }^{\mathrm{b}}$ The presence of human immune deficiency virus (HIV) infection or long term treatment with immunosuppressive drugs such as glucocorticoids, cyclosporine or azathioprine

${ }^{c}$ A scoring is applied. An HScore of $\geq 169$ has $93 \%$ sensitivity and $86 \%$ specificity for HLH. A cut-off value of $\geq 60$ for MH score discriminated best between pHLH and MAS

${ }^{\mathrm{d}}$ In a sJIA patient with fever and Ferritin $>684 \mathrm{ng} / \mathrm{ml}$, the presence of two additional parameters has a sensitivity of $73 \%$ and specificity of $99 \%$ for this score 


\section{HScore}

This score is developed to estimate the individual's risk of reactive HPS for both primary and secondary HLH. Clinical and laboratory features scored are given in Table 1 [28]. For this scoring, the following nine variables are used: Three clinical variables (underlying immunosuppression, high fever, organomegaly), five biochemical variables (triglycerides, ferritin, serum transaminases, fibrinogen, presence of cytopenia) and one cytological (findings of hemophagocytosis in the bone marrow) (Table 1). The median score for patients with a positive pHLH diagnosis was 230 [interquartile range (IQR) 203-257 and 125 (IQR) 91-150] for patients with a negative diagnosis.

The probability of suffering from HPS was less than $1 \%$ for an HS score of $\leq 90$ and $99 \%$ for an HScore of $\geq 250$. A cutoff of 169 had $93 \%$ sensitivity and $86 \%$ specificity for HLH. Note that bone marrow hemophagocytosis is not mandatory for an HLH diagnosis. This scoring system is available online for general use (http://saintantoine.aphp.fr/score /). Ferritin values have prognostic value in septic patients, additionally [29].

\section{How to decide between HScore and HLH-2004 score}

A Belgian group addressed this issue in detail. At the onset of the disease, HScore was more effective than the HLH2004 criteria in accurately identifying HLH for both children and adults; Diagnostic sensitivity and specificity were 100 and $80 \%$ for children and 90 and $79 \%$ for adults, respectively. HScore's performance dropped to levels similar to the HLH2004 criteria, with $73 \%$ accuracy for the same specificity once the patient's clinical condition worsens. The authors concluded that HScore for children is generally more useful than the HLH-2004 criteria, and for adults, HScore is most useful only at the patient's initial presentation. The authors also concluded that the originally published cut-off value of 169 should optimally be adapted according to the target patient group of interest [38]. Another group addressed this issue in rheumatological diseases. And proposed an adopted cut-off value for a target population with various rheumatological diseases. In a cohort of 94 patients with rheumatological diseases (30 with HLH and 64 controls), the optimal cut-off value was found to be 190.5 (sensitivity $96.7 \%$ and specificity 98.4\%) [39].

\section{MH scoring}

Although both sHLH/MAS and pHLH are life-threatening conditions, the mortality rate in patients with pHLH is much higher. Before the era of treatment protocols involving aggressive chemotherapy and immunosuppression, only $5 \%$ of pHLH patients survived 1 year after diagnosis. Therefore, it is extremely important to start the HLH-2004 treatment protocol containing etoposide in patients with pHLH immediately. Yet, most patients with pHLH need hematopoietic stem cell transplantation as the final treatment [3]. In contrast, the treatment of sHLH/MAS depends on the clinical severity and may either be treated with a moderate increase in the corticosteroid dosage or aggressive immunosuppressives drugs may be favored as the first therapeutic approach [8].

For these reasons, it is important to differentiate pHLH from pHLH/MAS as early as possible. However, the diagnostic work-up required for pHLH takes time and may not be readily performed everywhere. In this instance, some clinical and laboratory features gain importance. In a known sJIA patient, the clinical diagnosis of MAS is relatively simple in the presence of typical clinical features, but when MAS coincides with the onset of sJIA it may be substantially more difficult to distinguish MAS from pHLH. According to data from a large series of international MAS cases in sJIA patients, approximately $23 \%$ of reported MAS episodes occurred at the onset of SJIA and mimicked the characteristics of the underlying disease [40]. The first attempt to determine the laboratory properties that will separate MAS from pHLH was performed by Lehmberg et al. [18]. An important issue of this report is that in $70 \%$ of MAS patients included in this study, clinical manifestations of MAS appeared before the diagnosis of sJIA. Neutrophil counts and CRP were significantly higher in MAS/sJIA patients, and high levels of sIL2Ra were observed more frequently in pHLH. Minoia et al. proposed a more sophisticated composite score to distinguish better between pHLH and MAS: The macrophage activation syndrome/Hemophagocytic Lymphohistiocytosis (MH) score. The creation of the MH score is based on a much larger data set (362 patients with MAS and 258 patients with HLH). The MH score consists of six demographic, clinical, and laboratory variables: Age of onset, neutrophil count, fibrinogen level, presence of splenomegaly, platelet count, and hemoglobin level. A multivariate analysis was done to assess the weight of each variable for its contribution to the diagnosis of pHLH. The MH score was initially developed based on the data of $80 \%$ of patients and then validated using the data of the remaining $20 \%$ of the patients. MH score performed extremely well in the validation. In this study, the MH score ranged from 0 to 123 , and the median value was 97 (1st-3rd quartile 75-123) and 12 (1st-3rd quartile 11-34) in pHLH and MAS, respectively. The probability of receiving a diagnosis of $\mathrm{pHLH}$ was less than one percent for a score of less than one and $99 \%$ for a score of $\geq 123$. The cut-off value of $\geq 60$ had the best performance in separating pHLH from MAS [41]. However, for cases other than sJIA such as SLE or Kawasaki disease, where cytopenia and liver enzyme elevations may also be related to the activity of the underlying diseases, 
the discriminatory value may be lower. In this case, it is advisable to make a decision based on the patient's history, clinical complaints, and response to treatment.

\section{sJIA-MAS classification criteria}

These are the criteria developed by Ravelli et al. to overcome some difficulties encountered in the diagnosis of MAS developing in sJIA cases (Table 1). An important difference from HLH-2004 is the absence of SCD25 measurement. The calculated sensitivity and specificity of this classification set was 73 and 99\%, respectively [35].

The HLH2004 criteria set is a reliable tool in the diagnosis of HLH. The HScore estimates best the risk of HLH, and the MH score differentiates reliably between MAS and pHLH in pediatric cases. HScore is more accurate when used at the onset of the disease in adult patients, but cut-off values recommended for HScore may vary depending on the underlying disease. It is advisable to use the 2016 classification criteria to assess MAS in the course of sJIA.

As described above, HLH is a life-threatening medical condition. Early diagnosis and rapid intervention are lifesaving. It should be noted that the sHLH-cytokine storm may be the main reason for the rapid deterioration seen in a COVID-19 patient.

\section{Treatment}

Despite treatment with the HLA-2004 protocol, most patients with pHLH need an allogeneic stem cell transplant. Secondary forms and MAS rarely necessitate transplantation. In these cases, triggering factors such as infection, malignancy, and medication should be searched for. Remission is possible with a combined immunosuppressive treatment in sHLH/MAS cases. Early use of high-dose steroids can be successful alone, but more than half of reported adult cases are steroid-resistant. Unlike pHLH, patients rarely need hemopoietic stem cell transplantation due to MAS developing as a result of severe sJIA [42]. Carter et al. favor an immediate treatment with $1 \mathrm{~g}$ of intravenous methylprednisolone per day for 3-5 days combined with IVIG $1 \mathrm{~g} / \mathrm{kg}$ for 2 days (consider repeating every 14 days due to its half-life of 14-21 days) as the first-line treatment of sHLH [23]. The emergence of established HLH features or clinical deterioration despite treatment may necessitate the early initiation of the IL-1 blocker, Anakinra [23]. In our personal experience, when caught early in the course, the patient often relieves with the elimination of the triggering factors (such as medication] and a medium dose of corticosteroid therapy. Evidence in sJIA-related MAS suggests that early use of anakinra and IL-1 blockade would also be beneficial in the adult MAS population. Anakinra is effective in MAS treatment when corticosteroids, IVIG, cyclosporin, and etoposide fail to control the disease for most of the time only in combination with corticosteroids [43]. It is encouraging that the use of Anakinra is associated with an improved outcome in patients with sepsis and MAS features, and gives an appropriate signal for safe use in the context of sHLH, even when triggered by infection [44]. In refractory MAS cases, doses of $100 \mathrm{mg}$ anakinra four times a day may be required to achieve remission [45]. Anakinra is safely used in the treatment of autoinflammatory diseases, such as sJIA and FMF in rheumatology outpatient clinics.

Some studies of anakinra, canakinumab, and rilonacept reported that IL-1 blockade alone is not sufficient to prevent MAS in the course of sJIA. In these studies, corticosteroids, cyclosporin, and/or other drugs had to be added to treat MAS patients [23]. Interestingly, tocilizumab is useful in the treatment of HLH. However, MAS has also been reported in patients receiving tocilizumab. In these cases, clinical and laboratory findings of MAS such as lower ferritin levels, frequency of hepatomegaly, and normal CRP may become less subtle under tocilizumab treatment [46]. The cytokine storm seen in the course of COVID-19 is effectively treated with tocilizumab or anakinra $[11,47]$.

Rituximab may have a place in the treatment in combination with other drugs and has been shown to reduce EBV viral load, serum ferritin levels, and to improve the overall clinical outcome in patients with EBV-related HLH [18]. Already, the first cases of MAS in association with COVID19 cases treated successfully with JAK inhibitors such as Baricitinib and IL-1 or IL-6 blockers are accumulating [47].

\section{Conclusion}

HLH may be triggered by genetic conditions, infections including COVID-19, malignancies, autoimmune-autoinflammatory diseases, and some drugs. HLH should be suspected in patients with unexplained progressive fever, cytopenia, ARDS, neurological and renal impairment. Differentiation between the primary and secondary forms of HLH is utterly important, since primary forms of HLH require complicated treatments such as hematopoietic stem cell transplantation. As the COVID-19 pandemic develops, large numbers of patients with rare complications of viral infections such as HLH accumulate. Increasing cases of COVID-19 and its severe complications such as the cytokine storm and HLH may necessitate a closer collaboration of rheumatologists and hematologists with intensive care physicians, infectious disease specialists, and pneumologists, who are more likely to treat these patients in the first place. Early recognition of Hemophagocytic lymphohistiocytosis and its severe complication of cytokine storm is possible only using the diagnostic sets of criteria and by knowing their shortcomings and advantages 
in specific patient groups. Further studies addressing the performance of these criteria sets in the diagnosis in the setting of COVID-19 is necessary.

\begin{abstract}
Author contributions The author MS collected data and wrote the manuscript. The authors GTS and IA carefully reviewed the data from the perspective of a hematologist. And the author PA reviewed the article for both immunologic and rheumatologic aspects, prepared tables and figures, translated manuscript into English, and gave the manuscript's final form.
\end{abstract}

Funding No funding is used for the preparation of the manuscript.

\section{Compliance with ethical standards}

Conflict of interest Authors SM, AP, AI, and GTS declare that they have no conflict of interest.

Ethics approval Not applicable.

Consent to participate Not applicable.

Consent for publication Not applicable.

Availability of data and material The search algorithm for cited articles is given in Fig. 2.

Code availability Not applicable.

Disclaimer No part of the review is copied or published elsewhere.

\section{References}

1. Ramos-Casals M, Brito-Zerón P, López-Guillermo A, Khamashta MA, Bosch X (2014) Adult haemophagocytic syndrome. Lancet 26 383(9927):1503-1516. https://doi.org/10.1016/s0140 $-6736(13) 61048-\mathrm{x}$

2. Al-Samkari H, Berliner N (2018) Hemophagocytic lymphohistiocytosis. Annu Rev Pathol 13:27-49. https://doi.org/10.1146/annur ev-pathol-020117-043625

3. Jordan MB, Allen CE, Weitzman S, Filipovich AH, McClain KL (2011) How I treat hemophagocytic lymphohistiocytosis. Blood. 118:4041-4052. https://doi.org/10.1182/blood-2011-03-278127

4. Morimoto A, Nakazawa Y, Ishii E (2016) Hemophagocytic lymphohistiocytosis: pathogenesis, diagnosis, and management. Pediatr Int 58:817-825. https://doi.org/10.1111/ped.13064

5. Janka GE (2019) History of hemophagocytic lymphohistiocytosis. In: Cronand RQ, Behrens EM (eds) Cytokine storm syndrome. Springer Nature, Switzerland, pp 3-16

6. Silverman DE (2019) The history of macrophage activation syndrome in autoimmune diseases. In: Cronand RQ, Behrens EM (eds) Cytokine storm syndrome. Springer Nature, Switzerland, pp 17-30

7. Schimuzu M (2019) Clinical features of cytokine storm syndrome. In: Cronand RQ, Behrens EM (eds) cytokine storm syndrome. Springer Nature, Switzerland, pp 31-42

8. Rosado FG, Gopal P (2019) Laboratory features and pathology of the cytokine storm syndrome. In: Behrens EM (ed) Cronand RQ. Springer Nature, Switzerland, pp 43-60
9. Osugi Y, Hara J, Tagawa S, Takai K, Hosoi G, Matsuda Y et al (1997) Cytokine production regulating Th1 and Th2 cytokines in hemophagocytic lymphohistiocytosis. Blood 89:4100-4103

10. Mehta P, McAuley D, Brown M, Sanchez E, Tattersall RS, Manson J (2020) COVID-19: consider cytokine storm syndrome and immunosuppression. Lancet 395(10229):1033-1034. https ://doi.org/10.1016/s0140-6736(20)30628-0

11. Sarzi-Puttini P, Giorgi V, Sirotti S, Marotto D, Ardizzone S, Rizzardini G, Antinori S, Galli M (2020) COVID-19, cytokines and immunosuppression: what can we learn from severe acute respiratory syndrome? Clin Exp Rheumatol 38(2):337-342

12. Crayne CB, Albeituni S, Nichols KE, Cron RQ (2019) The immunology of macrophage activation syndrome. Front Immunol 10:119. https://doi.org/10.3389/fimmu.2019.00119 (eCollection 2019)

13. Weaver LK, Behrens EM (2014) Hyperinflammation, rather than hemophagocytosis, is the common link between macrophage activation syndrome and hemophagocytic lymphohistiocytosis. Curr Opin Rheumatol 26(5):562-569. https://doi.org/10.1097/ BOR.0000000000000093

14. Cetica V, Sieni E, Pende D, Danesino C, De Fusco C, Locatelli F, Micalizzi C et al (2016) Genetic predisposition to hemophagocytic lymphohistiocytosis: report on 500 patients from the Italian registry. J Allergy Clin Immunol 137(1):188196.e4. https://doi.org/10.1016/j.jaci.2015.06.048

15. Ericson KG, Fadeel B, Andersson M, Gudmundsson GH, Gürgey A, Yalman V, Janka G et al (2003) Sequence analysis of the granulysin and granzyme B genes in familial hemophagocytic lymphohistiocytosis. Hum Genet 112(1):98-99. https://doi. org/10.1007/s00439-002-0841-0

16. ZurStadt U, Beutel K, Kolberg S, Schneppenheim R, Kabisch H, Janka G, Hennies HC (2006) Mutation spectrum in children with primary hemophagocytic lymphohistiocytosis: molecular and functional analyses of PRF1, UNC13D, STX11, and RAB27A. Hum Mutat 27(1):62-68. https://doi.org/10.1002/ humu. 20274

17. Ammann S, Lehmberg K, Zur Stadt U, Janka G, Rensing-Ehl A, Klemann C et al (2017) Primary and secondary hemophagocytic lymphohistiocytosis have different patterns of T-cell activation, differentiation, and repertoire. Eur J Immunol 47:364-373

18. Lehmberg K, Pink I, Eulenburg C, Beutel K, Maul-Pavicic A, Janka G (2013) Differentiating macrophage activation syndrome in systemic juvenile idiopathic arthritis from other forms of hemophagocytic lymphohistiocytosis. J Pediatr 162:1245-1251. https://doi.org/10.1016/j.jpeds.2012.11.081

19. Strippoli R, Caiello De Benedetti IF (2013) Reaching the threshold: a multilayer pathogenesis of macrophage activation syndrome http://www.jrheum.org/content/40/6/761. J Rheumatol 40:761767. https://doi.org/10.3899/jrheum.121233

20. Fukaya S, Yasuda S, Hashimoto T, Kataoka H, Horita T, Atsumi T, Koike T (2008) Clinical features of hemophagocytic syndrome in patients with systemic autoimmune diseases: analysis of 30 cases. Rheumatology (Oxford) 47:1686-1691. https://doi. org/10.1093/rheumatology/ken342

21. Arlet JB, Le TH, Marinho A, Amoura Z, Wechsler B, Papo T, Piette JC (2006) Reactive haemophagocytic syndrome in adultonset Still's disease: a report of six patients and a review of the literature. Ann Rheum Dis 65:1596-1601

22. Canna SW, de Jesus AA, Gouni S, Brooks SR, Marrero B, Liu $\mathrm{Y}$ et al (2014) An activating NLRC4 inflammasome mutation causes autoinflammation with recurrent macrophage activation syndrome. Nat Genet 46:11406. https://doi.org/10.1038/ng.3089

23. Carter SJ, Tattersall RS, Ramanan AV (2019) Macrophage activation syndrome in adults: recent advances in pathophysiology, diagnosis, and treatment. Rheumatology 58:5-17. https://doi. org/10.1093/rheumatology/key006 
24. Paules CI, Marston HD, Fauci AS (2020) Coronavirus infections-more than just the common cold. JAMA 323(8):707-708. https://doi.org/10.1001/jama.2020.0757

25. Huang C, Wang Y, Li X, Ren L, Zhao J, Hu Y, Zhang L, Fan G, Xu J, Gu X (2020) Clinical features of patients infected with 2019 novel coronavirus in Wuhan, China. Lancet 395(10223):497-506. https://doi.org/10.1016/S0140-6736(20)30183-5

26. Misra DP, Agarwal V, Gasparyan AY, Zimba O (2020) Rheumatologists' perspective on coronavirus disease 19 (COVID-19) and potential therapeutic targets. Clin Rheumatol. https://doi. org/10.1007/s10067-020-05073-9

27. Ravelli A, Grom AA, Behrens E, Cron RQ (2012) Macrophage activation syndrome as part of systemic juvenile idiopathic arthritis: diagnosis, genetics, pathophysiology, and treatment. Genes Immun 13:289-298. https://doi.org/10.1038/gene.2012.3

28. Fardet L, Galicier L, Lambotte O, Marzac C, Aumont C, Chahwan D, Coppo P, Hejblum G (2014) Development and validation of the HScore, a score for the diagnosis of reactive hemophagocytic syndrome. Arthritis Rheumatol 66(9):2613-2620. https://doi. org/10.1002/art.38690

29. Grangé S, Buchonnet G, Besnier E, Artaud-Macari E, Beduneau $\mathrm{G}$ et al (2016) The use of ferritin to identify critically ill patients with secondary hemophagocytic lymphohistiocytosis. Crit Care Med. 44(11):e1045-e1053. https://doi.org/10.1097/CCM.00000 00000001878

30. Minoia F, Davì S, Horne A, Demirkaya E, Bovis F, Li C, Lehmberg K et al (2014) Clinical features, treatment, and outcome of macrophage activation syndrome complicating systemic juvenile idiopathic arthritis: a multinational, multicenter study of 362 patients. Arthritis Rheumatol 66:3160-3169. https://doi. org/10.1002/art.38802

31. Kim M-M, Yum M-S, Choi H-W, Ko TS, Im HJ, Seo JJ et al (2012) Central nervous system (CNS) involvement is a critical prognostic factor for hemophagocytic lymphohistiocytosis. Korean J Hematol 47:27380. https://doi.org/10.5045/kjh.2012.47.4.273

32. Aulagnon F, Lapidus N, Canet E, Galicier L, Boutboul D, Peraldi MN et al (2015) Acute kidney injury in adults with hemophagocytic lymphohistiocytosis. Am J Kidney Dis 65:851-859. https:// doi.org/10.1053/j.ajkd.2014.10.012

33. Hadchouel M, Prieur AM, Griscelli C (1985) Acute hemorrhagic, hepatic, and neurologic manifestations in juvenile rheumatoid arthritis: possible relationship to drugs or infection. J Pediatr 106:561-566. https://doi.org/10.1016/s0022-3476(85)80072-x

34. Ravelli A, Minoia F, Davi S, Horne A, Bovis F, Pistorio A et al (2016) Expert consensus on dynamics of laboratory tests for diagnosis of macrophage activation syndrome complicating systemic juvenile idiopathic arthritis. RMD Open 2:e000161. https://doi. org/10.1136/rmdopen-2015-000161 (eCollection 2016)

35. Ravelli A, Minoia F, Davi S, Horne A, Bovis F, Pistorio A et al (2016) 2016 Classification criteria for macrophage activation syndrome complicating systemic juvenile idiopathic arthritis: a European League Against Rheumatism/American College of Rheumatology/Paediatric Rheumatology International Trials Organisation collaborative initiative. Ann Rheum Dis 75:481-489. https://doi. org/10.1136/annrheumdis-2015-208982

36. Li X, Geng M, Peng Y, Meng L, Lu S (2020) Molecular immune pathogenesis and diagnosis of COVID19. J Pharm Anal. https:// doi.org/10.1016/j.jpha.2020.03.001
37. Henter JI, HorneA Maurizio A, Egeler RM, Filipovich AH, Imashuku S et al (2007) HLH-2004: diagnostic and therapeutic guidelines for hemophagocytic lymphohistiocytosis. Pediatr Blood Cancer 48(2):124-131. https://doi.org/10.1002/pbc.21039

38. Debaugnies F, Mahadeb B, Ferster A, Meuleman N, Rozen L, Demulder A, Francis Corazza F (2016) Performances of the $\mathrm{H}$-score for diagnosis of hemophagocytic lymphohistiocytosis in adult and pediatric patients. Am J Clin Pathol 145:862-870. https ://doi.org/10.1093/ajcp/aqw076

39. Batu ED, Erden A, Seyhoglu E, Kilic L, Buyukasik Y, Karadag O et al (2017) Assessment of the HScore for reactive haemophagocytic syndrome in patients with rheumatic diseases. Scand J Rheumatol 46:44-48. https://doi.org/10.3109/03009742.2016.1167951

40. Kostik MM, Dubko MF, Masalova VV, Snegireva LS, Kornishina TL, Chikova IA et al (2015) Identification of the best cutoff points and clinical signs specific for early recognition of macrophage activation syndrome in active systemic juvenile idiopathic arthritis. Semin Arthritis Rheum 44(4):417-422. https:// doi.org/10.1016/j.semarthrit.2014.09.004

41. Minoia F, Bovis F, Davì S, Insalaco A, Lehmberg K, Shenoi K et al (2017) Development and initial validation of the MH score a diagnostic tool that differentiates primary hemophagocytic lymphohistiocytosis from macrophage activation syndrome. J Pediatr 189:72-78.e3. https://doi.org/10.1016/j.jpeds.2017.06.005

42. Wulffraat NM, Rijkers GT, Elst E, Brooimans R, Kuis W (2003) Reduced perforin expression in systemic juvenile idiopathic arthritis is restored by autologous stem-cell transplantation. Rheumatology (Oxford) 42:3759. https://doi.org/10.1093/rheumatolo gy/keg074

43. NHS England Clinical Commissioning Policy Statement: Biologic Therapies for the Treatment of Juvenile Idiopathic Arthritis (JIA). In https://www.england.nhs.uk/commissioning/wp-content/ uploads/sites/12/2015/10/e03pd-bio-therapies-jia-oct15.pdf. Last accessed 14th Apr 2020

44. Shakoory B, Carcillo JA, Chatham WW, Amdur RL, Zhao H, Dinarello CA et al (2016) Interleukin1 receptor blockade is associated with reduced mortality in sepsis patients with features of macrophage activation syndrome: reanalysis of a prior phase III trial. Crit Care Med 44:275-281. https://doi.org/10.1097/CCM.00000 00000001402

45. Kahn PJ, Cron RQ (2013) Higher-dose Anakinra is effective in a case of medically refractory macrophage activation syndrome. J Rheumatol 40:743-744. https://doi.org/10.3899/jrheum.121098

46. Yokota S, Itoh Y, Morio T, Sumitomo N, Daimaru K, Minota S (2015) Macrophage activation syndrome in patients with systemic juvenile idiopathic arthritis under treatment with tocilizumab. J Rheumatol 42(4):712-722. https://doi.org/10.3899/jrheum.14028 8 (Epub 2015 Feb 15)

47. Ferro F, Elefante E, Baldini C, Bartoloni E, Puxeddu I, Talarico R, Mosca M, Bombardieri S (2020) COVID-19: the new challenge for rheumatologists. Clin Exp Rheumatol 38:175-180 (Epub 2020 Mar 24)

Publisher's Note Springer Nature remains neutral with regard to jurisdictional claims in published maps and institutional affiliations. 


\section{Affiliations}

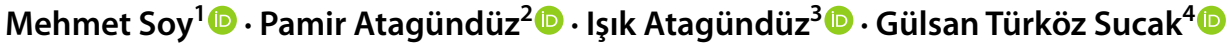

Mehmet Soy

mhmtsoy@gmail.com

Işık Atagündüz

ikatagunduz@gmail.com

Gülsan Türköz Sucak

gulsan.sucak@medicalpark.com.tr

1 Internal Medicine and Rheumatology, Division of Rheumatology, Department of Internal Medicine, Faculty of Medicine, Bahcelievler MedicalPark Hospital, Altınbas University, Istanbul, Turkey
2 Internal Medicine and Rheumatology, Division of Rheumatology, Department of Internal Medicine, Faculty of Medicine, Marmara University, Istanbul, Turkey

3 Internal Medicine and Hematology, Division of Hematology, Department of Internal Medicine, Faculty of Medicine, Marmara University, Istanbul, Turkey

4 Internal Medicine and Hematology, Division of Hematology and Bone Marrow Transplantation Unit, Bahcelievler MedicalPark Hospital, Istanbul, Turkey 